\title{
Oxymetholone Measurement
}

National Cancer Institute

\section{Source}

National Cancer Institute. Oxymetholone Measurement. NCI Thesaurus. Code C75388.

The determination of the amount of oxymetholone present in a sample. 